\title{
EFEITO DA MASSA E DA FORMA DE PROCESSAMENTO DAS SEMENTES NO PODER COAGULANTE DA MORINGA
}

\author{
Mateus Pimentel de Matos ${ }^{1}$, Antonio Teixeira de Matos², Edson Faria da Silva $^{3}$, Valdeir Eustáquio Júnior ${ }^{4}$
}

\section{RESUMO}

Pouco se sabe sobre a influência da qualidade e da forma de processamento da semente no poder coagulante do extrato de sementes de moringa. Assim, a realização deste trabalho objetivou avaliar o poder coagulante e xenobiótico das sementes de acordo com a faixa de massa e a sua forma de processamento (descascadas e não descascadas) para preparo do coagulante. Para isso, analisou-se a água superficial com alta turbidez coletada em uma represa. Nas amostras foram adicionados extratos preparados com sementes divididas em três classes de massa (menor ou igual a 0,20 g, entre 0,20 e 0,30 g, e maior ou igual a $0,30 \mathrm{~g}$ ); sementes descascadas, sem discriminação de massa; e apenas cascas; além da testemunha (sem adição de coagulante). Além disso, foram analisados os teores de nitrogênio e proteína no material. Os resultados indicaram que as maiores eficiências na remoção da turbidez e de coliformes termotolerantes (E. coli) estão associadas ao teor de proteína bruta nos materiais utilizados no preparo do extrato. Aumento na coagulação/floculação/sedimentação de sólidos e na remoção de coliformes foram obtidos com a adição de extratos preparados com sementes de massa maior que $0,20 \mathrm{~g}$, ou com sementes descascadas. No que se refere às sementes de massa menor que $0,20 \mathrm{~g}$, maiores eficiências na remoção de turbidez e coliformes são obtidas quando os extratos são preparados com sementes descascadas.

Palavras-chave: bactericida, colimetria, tratamento de água, turbidez.

\section{ABSTRACT \\ EFFECT OF THE MASS AND FORM OF SEED PROCESSING ON THE COAGULANT POWER OF MORINGA}

Little is known regarding the influence of quality and form of seed processing on the coagulation power of the Moringa seed extract. Thus, this work sought to evaluate the coagulant and xenobiotic power of seeds according to the mass range and its form of processing (shelled or unshelled seeds). For this, surface water with high turbidity, collected in from a reservoir was analyzed. To the samples extracts prepared from the seeds in three mass classes were added (less than or equal to $0.20 \mathrm{~g}$, between 0.20 and $0.30 \mathrm{~g}$, and greater than or equal to $0.30 \mathrm{~g}$ ), shelled seeds without discrimination by mass, just shells, as well as the control (without addition of the coagulant). Moreover, the contents of nitrogen and crude protein in the material were also quantified. The results indicated that the highest efficiencies of turbidity and fecal coliform (E. coli) removal are associated with the crude protein content in the material used in preparation of the extract. Increases in coagulation/flocculation/sedimentation of solids and in coliform removal were obtained with extracts prepared with addition of seed mass greater than $0.20 \mathrm{~g}$ with shelled seeds. With regard to seeds of mass less than $0.20 \mathrm{~g}$, higher efficiencies of turbidity and coliform removal are obtained when the extracts are prepared from unshelled seeds

Keywords: bactericidal, colimetric, turbidity, water treatment.

\section{Recebido para publicação em 21/09/2013. Aprovado em 24/03/2014.}

1 - Engenheiro Agrícola e Ambiental, Doutorando em Saneamento, DESA, UFMG, matmatos_eaa@yahoo.com.br

2 - Professor do Departamento de Engenharia Agrícola, DEA, CCA, UFV, atmatos@ufv.br.

3 - Engenheiro Agrícola e Ambiental, Doutorando em Recursos Hídricos e Ambientais, DEA, CCA, UFV, edson.silva@ufv.br

4 - Engenheiro Agrícola e Ambiental, Mestre em Recursos Hídricos e Ambientais, DEA, CCA, UFV, vejunior@yahoo.com.br 


\section{INTRODUÇ̃̃O}

A coagulação consiste no conjunto de ações físicas e reações químicas, com duração de poucos segundos, entre o coagulante, usualmente um sal de alumínio ou de ferro, a água e as impurezas presentes. Apresenta-se em três fases: (i) formação das espécies hidrolisadas do sal quando disperso na água, (ii) desestabilização das partículas coloidais e suspensas dispersas na massa líquida e (iii) agregação dessas partículas para formação dos flocos (DI BERNARDO; DANTAS, 2005; SANTOS et al., 2007).

O sulfato de alumínio é o agente coagulante mais comumente utilizado no Brasil, em razão da alta eficiência na remoção de sólidos em suspensão da água e pelo seu relativo baixo custo. No entanto, esse sal apresenta algumas desvantagens, tais como: possibilidade de aumentar significativamente as concentrações de residual de alumínio nas águas tratadas (WANG et al., 2010); geração de lodo com elevada concentração de alumínio, o que dificulta a disposição final desse material no ambiente, além de ser apontado como possível causador do mal de Alzheimer (FERREIRA et al., 2008). O uso de sais de alumínio tem outro inconveniente, que é a necessidade de produtos químicos para correção do $\mathrm{pH}$, requerido pelo consumo de alcalinidade pelo sulfato de alumínio, o que encarece os custos do tratamento (SILVA et al., 2007).

Atualmente, tem-se procurado alternativas para tornar o tratamento de água com alta eficiência, baixo custo e menos agressivo ao meio ambiente. Dentre os processos de tratamento passíveis de serem adotados, principalmente em comunidades de pequeno porte, está a filtração lenta, recomendável para águas que apresentem baixa turbidez e intensidade de cor (PATERNIANI et al., 2011). O processo consiste em fazer a água passar através de um meio granular com a finalidade de remover impurezas físicas, químicas e biológicas.

O uso de coagulantes orgânicos que possam ser, ao mesmo tempo, de baixa toxicidade, que gerem menor quantidade de lodo, menor problema quanto à disposição final; maior biodegradabilidade, podendo os mesmos serem produzidos no próprio local de tratamento, tais como o extrato de semente de moringa (Moringa oleifera), pode ser outra opção.
Lo Monaco et al. (2010) observaram eficiência na remoção de turbidez de até $98,1 \%$ quando utilizaram $0,4 \mathrm{~g}$ de sementes por litro de água (essa relação será utilizada, como $\mathrm{g} \mathrm{L}^{-1}$, em todo o trabalho), no tratamento de água superficial proveniente do reservatório do Ribeirão São Bartolomeu, localizado no campus da Universidade Federal de Viçosa, com turbidez inicial de 285 UNT. Por sua vez, Abdulsalam et al. (2007), utilizando concentração de $0,18 \mathrm{~g} \mathrm{~L}^{-1}$, obtiveram eficiência $82,4 \%$ na remoção de turbidez de águas superficiais brutas de Maiduguri, Nigéria, com turbidez inicial de 17 UNT. Verificaram-se eficientes remoções na turbidez e/ ou coliformes do extrato de sementes de moringa no tratamento de águas residuárias de criatórios de camarão (CRUZ et al., 2007), águas residuárias do processamento de frutos do cafeeiro (MATOS et al., 2007), em efluentes de reator anaeróbio (SILVA et al., 2007) e de águas superficiais (PATERNIANI et al., 2009; PRITCHARD et al., 2010; SENGUPTA et al., 2012).

Sementes de moringa têm elevadas concentrações de proteínas e lipídios, sendo as primeiras as principais responsáveis pelo processo de redução na turbidez e clarificação da água. Ndabigengesere et al. (1995) afirmaram que proteínas de alto peso molecular são mais eficientes no processo de neutralização de cargas e adsorção de partículas sólidas, proporcionando maior floculação. Jahn (1986), por sua vez, ao estudar duas espécies de moringa (M. stenopetala e M. oleifera), verificou que a remoção de coliformes da água se devia à presença de substâncias xenobióticas nos cotilédones da semente da moringa.

Considerando-se que são as proteínas as principais responsáveis pelo efeito coagulante das sementes de moringa, por hipótese, sementes de maior massa, geralmente as de maior tamanho, quando trituradas, apresentariam maior poder coagulante. De forma semelhante, se a casca possuir menor teor de proteína bruta e não possuir substâncias xenobióticas, a sua inclusão, por ocasião do preparo do extrato de sementes de moringa, pode, também, ter efeito negativo na eficiência do coagulante e bactericida.

Assim, no presente trabalho, objetivouse avaliar o poder coagulante das sementes de moringa, de acordo com a faixa de massa e a forma

\section{REVENG}


de processamento das sementes (descascadas e não descascadas), no que se refere à remoção de turbidez e contagem de coliformes termotolerantes (E. coli) da água sob tratamento.

\section{MATERIAL E MÉTODOS}

A água em estudo foi coletada na represa da Hidráulica, pertencente à Universidade Federal de Viçosa (UFV), sendo as análises feitas no Laboratório de Qualidade da Água, do Departamento de Engenharia Agrícola (DEA) da mesma universidade.

As sementes de moringa foram colhidas em espécies arbóreas cultivadas em Viçosa-MG e, depois de secadas ao ar, em ambiente de sombra, foram separadas em três classes, de acordo com a massa: menores ou iguais a $0,20 \mathrm{~g}$, entre 0,20 e $0,30 \mathrm{~g}$ e maiores ou iguais a $0,30 \mathrm{~g}$. Sementes descascadas, não classificadas de acordo com sua massa, além de cascas retiradas de sementes, também foram utilizadas no preparo de extratos.

Os extratos foram preparados triturando-se 20 $\mathrm{g}$ de sementes (ou, no caso, cascas) em cada litro de água destilada. A trituração do material foi feita em liquidificador (volumes de $500 \mathrm{~mL}$, por vez, por ser a capacidade do copo do equipamento). As suspensões obtidas foram, então, filtradas em malha de $1 \mathrm{~mm}$. Retiraram-se alíquotas de 10 $\mathrm{mL}$ da suspensão filtrada (extrato) que, quando misturada à amostra de água superficial, coletada na Represa da Hidráulica, localizada no campus da Universidade Federal de Viçosa, proporcionou a obtenção de uma concentração de $0,4 \mathrm{~g}$ de sementes por litro da referida amostra de água a ser tratada.

$\mathrm{O}$ experimento foi realizado no delineamento em blocos casualizados, sendo as amostras submetidas a cinco tratamentos: T1: extrato preparado com sementes com casca, de massa menor ou igual a $0,20 \mathrm{~g}$; T2: extrato preparado com sementes com casca, de massa entre 0,20 e 0,30 g; T3: extrato preparado com sementes com casca, de massa maior ou igual a $0,30 \mathrm{~g}$; T4: extrato preparado com sementes descascadas; T5: extrato preparado apenas com cascas e T6: "testemunha", sem adição do extrato. Assim, com os tratamentos T1 a T3 visou-se observar a possível influência do tamanho das sementes, com o $\mathrm{T} 4$ a possibilidade de melhoria na eficiência do extrato preparado com sementes descascadas no tratamento da água. Com o tratamento T5, procurou-se avaliar o possível efeito deletério da casca na qualidade do extrato como agente coagulante.

As amostras foram misturadas e colocadas em agitação por $30 \mathrm{~s}$, a $160 \mathrm{rpm}$ e, posteriormente, a 15 rpm, por $15 \mathrm{~min}$, no aparelho denominado "Jar-test" em metodologia semelhante à utilizada no trabalho conduzido por Lo Monaco et al. (2010). Decorrido o tempo de mistura, as amostras foram deixadas em repouso, por duas horas, para sedimentação. Do sobrenadante, retiraram-se, então, alíquotas, nas quais foram analisadas turbidez, $\mathrm{pH}$ (para detecção de possíveis variações) e colimetria. Cada tratamento foi aplicado com quatro repetições (blocos).

A análise de coliformes (colimetria) foi feita usando o reagente Colilert como meio de cultura, utilizando-se a técnica indicadora de presença denominada Defined Substrate Technology (DST) (APHA et al., 2005), obtendo-se a contagem de coliformes termotolerantes (E. coli). No caso dessa análise, optou-se por utilizar alíquotas provenientes de apenas duas repetições (blocos).

Por fim, amostras de $0,20 \mathrm{~g}$ de sementes (contendo a casca) das três faixas de massa e apenas casca foram analisadas para se obter a concentração de nitrogênio total (NT). Para isso, utilizou-se o método Kjeldahl modificado (introdução do ácido salicílico, para quantificação das formas nítricas) (MATOS, 2012) e, com isso, o teor de proteína bruta $(\mathrm{PB}=6,25 \times \mathrm{NT}$ ) (SILVA, 1998). Para expressão dos resultados em relação à massa seca, foi necessária a obtenção do conteúdo de água do material. Para isso, o material foi secado a $65^{\circ} \mathrm{C}$, por $24 \mathrm{~h}$, seguido de secagem a 110 ${ }^{\circ} \mathrm{C}$, com pesagens efetuadas a cada uma hora até que a massa de material permanecesse constante. A concentração de nitrogênio obtida na massa fresca foi, então, corrigida. O experimento de quantificação de $\mathrm{N}$ foi conduzido no delineamento inteiramente casualizado, com três repetições.

As análises estatísticas consistiram em análise de variância e, quando significativa em nível de $5 \%$ de probabilidade, teste de médias (Dunnet ou Tukey), dependendo do tipo de comparação, em nível de $5 \%$ de probabilidade. 


\section{RESULTADOS E DISCUSSÃO}

Na Figura 1 apresenta-se o aspecto visual das amostras de água superficial, após terem sido submetidas aos diferentes tratamentos.

No Quadro 1, estão apresentados valores de $\mathrm{pH}$ nas suspensões proporcionadas pelos tratamentos aplicados e a realização do ensaio utilizando-se o aparelho "Jar-test".

Verificou-se que não ocorreram alterações no valor do $\mathrm{pH}$ da suspensão entre os tratamentos (teste de Tukey com 5\% de probabilidade) e nem entre os tratamentos e a testemunha (teste de Dunnet, em nível de 5\% de probabilidade). Dessa forma, conclui-se não ser necessária a adição de produtos químicos para controlar o $\mathrm{pH}$ da água em tratamento. Tais resultados corroboram o que foi obtido por Ndabigengesere et al. (1995), Silva et al. (2007) e Paterniani et al. (2009).

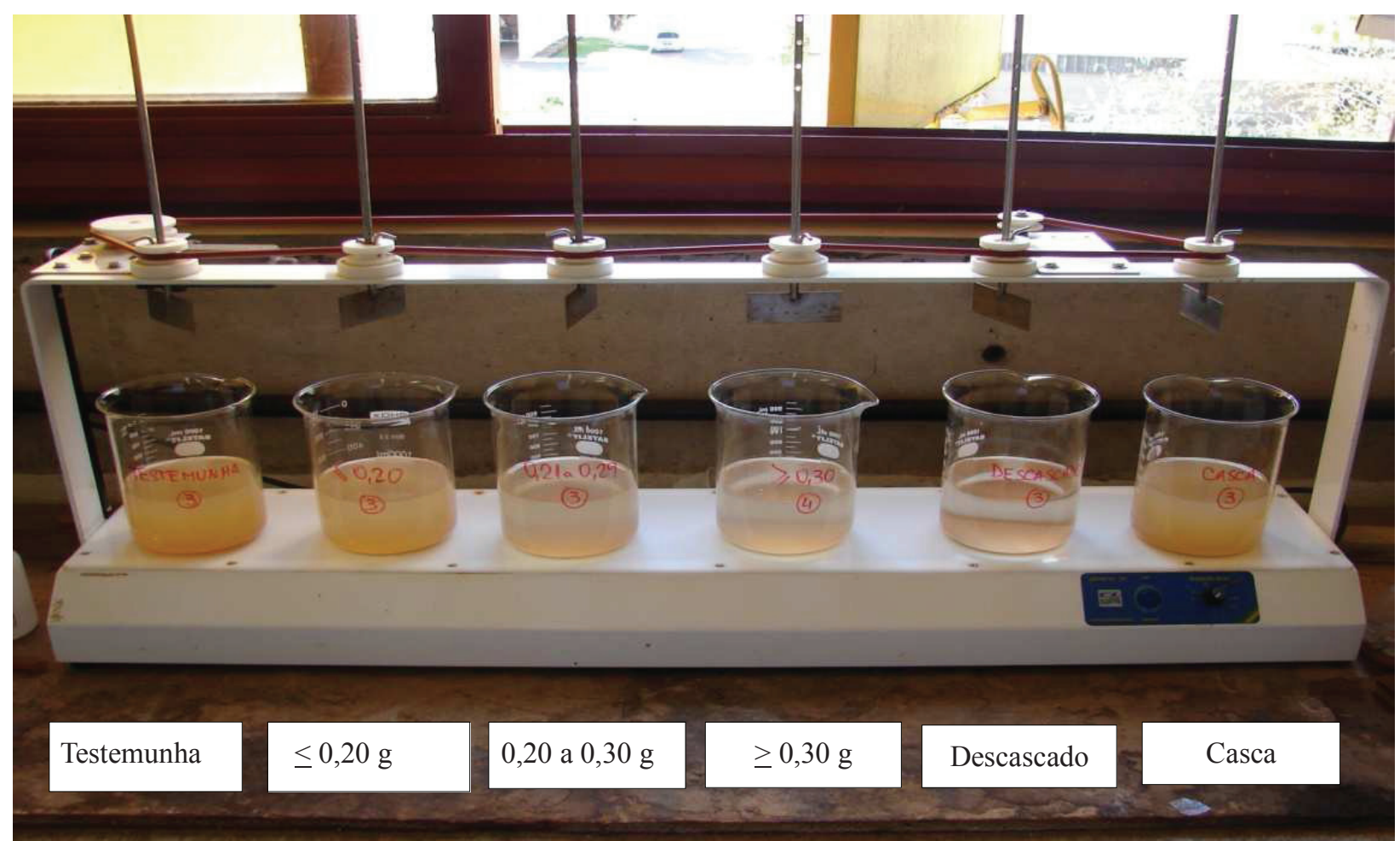

Figura 1. Comparativo entre a turbidez das amostras após terem sido submetidas aos diferentes tratamentos.

Quadro 1. Valores de $\mathrm{pH}$ nas amostras após terem sido submetidas aos tratamentos pré-estabelecidos

\begin{tabular}{lc}
\hline Tratamentos & pH médio \\
\hline Condição inicial & 7,3 \\
Testemunha & 7,2 \\
Extrato preparado com sementes de massa menor ou igual a $0,20 \mathrm{~g}$ & 7,2 \\
Extrato preparado com sementes de massa entre 0,20 e 0,30 g & 7,1 \\
Extrato preparado com sementes de massa $\geq 0,30 \mathrm{~g}$ & 7,4 \\
Extrato preparado com sementes descascadas & 7,4 \\
Extrato preparado apenas com cascas & 7,4 \\
\hline
\end{tabular}

\section{REVENG}


No Quadro 2 estão apresentados os valores médios de turbidez inicial na testemunha (sem adição de extratos) e obtidos com a adição de extratos preparados com sementes com casca, que apresentavam massa menor ou igual a $0,20 \mathrm{~g}$; de 0,20 a $0,30 \mathrm{~g}$; e maior ou igual a $0,30 \mathrm{~g}$, além daqueles preparados com sementes descascadas e com cascas. Na mesma tabela estão apresentados valores de eficiência na remoção da turbidez obtidos com a adição dos referidos extratos na água submetida aos diferentes tratamentos.

Verificou-se grande remoção de turbidez da água superficial com a utilização dos extratos de sementes, embora até mesmo na testemunha a remoção possa ser considerada razoável. A explicação para ter sido obtida remoção de 53,9\% na turbidez na testemunha deve-se à elevada quantidade de sólidos sedimentáveis na água coletada na represa (turbidez inicial de 797 UNT).

As maiores eficiências foram obtidas quando utilizados extratos preparados com sementes com massa maior que $0,30 \mathrm{~g}$ e com aqueles preparados com sementes descascadas. $\mathrm{O}$ extrato preparado com as cascas proporcionou resultados ainda piores que aqueles obtidos no tratamento testemunha, o que pode ser explicado pelo fato das cascas, além de não terem apresentado expressivo efeito coagulante, serem fonte de sólidos em suspensão para o meio, aumentando a turbidez. Arantes et al. (2010), pensando nesse possível aumento na concentração de sólidos com a introdução de material orgânico das próprias sementes, estudaram o uso de sachês para que se pudesse reduzir a turbidez na água a ser tratada. Os autores obtiveram turbidez de 76,9 UNT, com adição de extrato de sementes de moringa, e de até 5,5 UNT, quando isso foi feito por meio de sachês, em água destilada, sem, contudo, ter sido reduzido o teor de proteína na suspensão.

Aplicando o teste de Dunnet, com nível de $5 \%$ de probabilidade, verificaram-se diferenças significativas entre todos os tratamentos e o tratamento testemunha, indicando efetividade dos tratamentos, no que se refere à remoção de turbidez da água superficial. No caso do extrato preparado somente com cascas, houve aumento na turbidez, em relação à testemunha, devido à já comentada adição de sólidos suspensos no meio, sem ter havido significativo efeito coagulante do extrato.

Considerando-se que a casca exerça influência negativa na turbidez, acredita-se que extratos preparados com sementes descascadas proporcionem resultados melhores do que aqueles obtidos com extratos preparados com sementes de moringa contendo as cascas. Borba (2001) verificou que as maiores remoções de turbidez se deram quando os extratos foram preparados com a polpa da semente, tendo obtido eficiências de até 97,5\%. Usando sementes sem descascá-las (semente integral), a eficiência máxima diminuiu para 79,6\% e ao se usar apenas as cascas, as remoções foram em

Quadro 2. Turbidez média na água superficial e eficiência na sua remoção, de acordo com o tratamento recebido

\section{Tratamentos}

\section{Condição inicial}

Testemunha

Extrato preparado com sementes de massa menor ou igual a $0,20 \mathrm{~g}$

Extrato preparado com sementes de massa entre 0,20 e 0,30 g

Extrato preparado com sementes de massa maior ou igual a $0,30 \mathrm{~g}$

Extrato preparado com sementes descascadas

Extrato preparado apenas com cascas
Turbidez média final (UNT) remoção (\%) 
torno de 25,0\%. Ndabigengesere e Narasiah (1998) atribuem essa menor efetividade das sementes não descascadas à possível presença de sítios ativos na casca, que adsorvem as proteínas responsáveis pela coagulação. Os valores obtidos neste trabalho reforçam a expectativa de piores remoções quando os extratos são preparados utilizandose apenas cascas, e maior capacidade coagulante quando preparados com sementes descascadas. No entanto, esse último tratamento proporcionou eficiência próxima daquele em que foi adicionado extrato preparado com sementes de maior massa, sobretudo maior ou igual a $0,30 \mathrm{~g}$.

Ndabigengesere et al. (1995), ao compararem os resultados obtidos quando se adicionou extratos preparados com sementes sem casca com aqueles preparados com sementes contendo cascas, em água superficial com turbidez inicial de 426 UNT, verificaram que os últimos foram quase tão eficientes como os primeiros. Em ambos os tratamentos, as remoções estiveram em torno de $90 \%$. Os autores afirmaram que, em águas mais turvas (turbidez maior que 105 UNT), não é compensatório o dispendioso trabalho de descascar as sementes para preparar o coagulante.

No Quadro 3 estão apresentados os dados de turbidez média apenas nas amostras de água superficial submetidas aos tratamentos em que foram adicionados extratos de sementes de moringa.

Verifica-se que os três tratamentos mais eficientes na remoção de turbidez proporcionaram resultados na faixa citada por Muyibi e Evison (1995) como possível de remoção de turbidez com extratos de sementes de moringa (entre $80,0 \%$ e $99,5 \%$ ), sendo, entretanto, superiores aos resultados obtidos por Abdulsalam et al. (2007) $(82,4 \%)$, porém pouco inferiores aos obtidos por Lo Monaco et al. (2010) (98,1\%).
Não houve diferença significativa entre os tratamentos em que foi adicionado o extrato preparado com sementes contendo cascas e com massa maior ou igual a $0,30 \mathrm{~g}$ e aquele em que foi adicionado o extrato preparado com sementes não classificadas por massa, mas descascadas. Considerando que as sementes descascadas estão, em geral, na fração de massa média (entre 0,20 e $0,30 \mathrm{~g}$ ), especula-se que o efeito coagulante do extrato preparado com sementes nessa faixa de massa seja maior que o proporcionado pelo extrato preparado com sementes de massa maior ou igual a $0,30 \mathrm{~g}$, com cascas. Tais comparações são possíveis desde que se comparem extratos preparados com as mesmas massas de material. Esses resultados contrariam a afirmação de Ndabigengesere et al. (1995), que não recomendaram o descascamento das sementes quando a turbidez da água for superior a 105 UNT. Entretanto, se tratando de sementes com diversos tamanhos, com predomínio da faixa de massa média ou maior, o descascamento pode não propiciar ganho na remoção de turbidez que compense o esforço desprendido. No Quadro 4 estão apresentados os resultados das contagens de coliformes termotolerantes (E. coli) e a eficiência na sua remoção das amostras, após terem sido submetidas aos diferentes tratamentos.

Segundo Muyibi e Evision (1995), é possível remover de 90 a $99 \%$ de coliformes termotolerantes presentes na água utilizando-se apenas extrato de sementes de moringa como agente de desinfecção. Neste trabalho, somente a adição de extrato preparado com sementes de moringa de massa maior ou igual a $0,30 \mathrm{~g}$ proporcionou resultados que se aproximaram dessa faixa. Diferentemente do que foi observado em relação à turbidez, o fato de terem ou não as cascas junto às sementes não influenciaram nos resultados. Os resultados dos

Quadro 3. Turbidez média considerando-se apenas amostras submetidas aos tratamentos de adição de extratos de sementes.

\begin{tabular}{lc}
\hline Extrato & Turbidez média final (UNT) \\
\hline Sementes de massa menor ou igual a $0,20 \mathrm{~g}$ & $246 \mathrm{a}$ \\
Sementes de massa de massa entre $0,20 \mathrm{e} 0,30 \mathrm{~g}$ & $71 \mathrm{~b}$ \\
Sementes de massa maior ou igual a $0,30 \mathrm{~g}$ & $39 \mathrm{c}$ \\
Sementes descascadas & $19 \mathrm{c}$ \\
\hline Médias seguidas pela mesma letra, na coluna, não diferem entre si, pelo teste de Tukey, em nível de $5 \%$ de probabilidade.
\end{tabular}

346 REVENG

341-350p. ENGENHARIA NA AGRICULTURA, VIÇOSA - MG, V.22 N.4, JULHO / AGOSTO 2014 
Quadro 4. Contagem de coliformes termotolerantes (E. coli) e eficiência na sua remoção de amostras de água superficial, de acordo com o tratamento recebido.

\begin{tabular}{lcc}
\hline Tratamentos & $\begin{array}{c}\text { E. coli média } \\
(\mathbf{N M P} / \mathbf{1 0 0} \mathbf{~ m L})\end{array}$ & $\begin{array}{c}\text { Eficiência na remoção } \\
\mathbf{( \% )}\end{array}$ \\
\hline Condição inicial & 94,4 & - \\
Testemunha & 42,5 & 55 \\
Extrato preparado com sementes de massa menor ou igual a 0,20g & 82,9 & 12 \\
Extrato preparado com sementes de massa entre 0,20 e 0,30g & 25,1 & 73 \\
Extrato preparado com sementes de massa $\geq 0,30 \mathrm{~g}$ & 15,7 & 83 \\
Extrato preparado com sementes descascadas & 23,1 & 76 \\
Extrato preparado apenas com cascas & 343,0 & $*$ \\
\hline
\end{tabular}

* A contagem de E. coli encontrada foi superior ao valor inicial.

Quadro 5. Contagem de coliformes termotolerantes (E. coli) nas amostras de água superficial, considerandose apenas amostras submetidas aos tratamentos de adição de extratos de sementes.

Extratos

Sementes de massa menor ou igual a $0,20 \mathrm{~g}$

Sementes de massa de massa entre 0,20 e $0,30 \mathrm{~g}$

Sementes descascadas

Sementes de massa maior ou igual a $0,30 \mathrm{~g}$
Contagem média de $E$. coli (NMP/100 mL)
$25,1 \mathrm{~b}$

$23,1 \mathrm{~b}$

$15,7 \mathrm{~b}$

Médias seguidas pela mesma letra, na coluna, não diferem entre si, pelo teste de Tukey, em nível de $5 \%$ de probabilidade.

testes estatísticos estão apresentados a seguir, no Quadro 5.

Observaram-se valores 3,6 vezes maiores na contagem de E. coli após a amostra de água superficial ser tratada com a adição de extrato preparado apenas com cascas de semente de moringa. Suspeita-se que isso esteja associado ao aumento na disponibilidade de abrigo e alimento para os micro-organismos, sem, contudo, ter ocorrido efeito bactericida do extrato, o que possibilitou a proliferação desses microorganismos. No Quadro 5 estão apresentados os números mais prováveis de organismos (E. coli) nos tratamentos em que foram adicionados extratos de sementes de moringa (descascadas ou não), além da análise estatística dos dados.

Analisando-se os resultados apresentados na tabela acima, verificou-se, novamente, que as maiores eficiências na remoção de $E$. coli ocorreram nas amostras submetidas aos tratamentos em que foram adicionados extratos preparados com sementes de maior massa e com sementes descascadas. Observa-se, também, que não há diferença significativa entre os tratamentos em que houve a adição de extratos preparados com sementes de 0,20 a $0,30 \mathrm{~g}$, descascadas e com massa maior ou igual a $0,30 \mathrm{~g}$. Extratos preparados com sementes de pequena massa (menor ou igual a $0,20 \mathrm{~g}$ ) proporcionaram menor remoção de $E$. coli de águas superficiais que os outros extratos.

As concentrações de nitrogênio e proteína bruta em sementes com casca, descascadas e apenas nas cascas estão apresentadas no Quadro 6. 
Quadro 6. Concentração de nitrogênio $(\mathrm{N})$ e de proteína bruta $(\mathrm{PB})$ em sementes com casca, descascadas e apenas cascas.

\begin{tabular}{lcc}
\hline \multirow{2}{*}{ Material } & \multicolumn{2}{c}{ Teor médio $\left(\mathbf{d a g}_{\mathbf{~ k g}}{ }^{-1}\right)$} \\
& $\mathbf{N}$ & $\mathbf{P B}$ \\
\hline Sementes de massa menor ou igual a $0,20 \mathrm{~g}$ & 4,36 & 27,28 \\
Sementes com massa entre 0,20 e $0,30 \mathrm{~g}$ & 5,69 & 35,58 \\
Sementes com massa maior ou igual a 0,30 g & 5,16 & 32,23 \\
Descascadas & 7,05 & 44,07 \\
Cascas & 2,58 & 16,13 \\
\hline
\end{tabular}

Quadro 7. Teores médios de proteína bruta (PB) em sementes com cascas, descascadas e apenas cascas.

\begin{tabular}{lc}
\hline Material & PB $\left(\mathbf{d a g} \mathbf{~ k g}^{-1}\right)$ \\
\hline Sementes de massa menor ou igual a 0,20 g & $44,07 \mathrm{a}$ \\
Sementes com massa entre 0,20 e 0,30 g & $35,58 \mathrm{~b}$ \\
Sementes com massa maior ou igual a 0,30 g & $32,23 \mathrm{bc}$ \\
Descascadas & $27,28 \mathrm{c}$ \\
Cascas & $16,13 \mathrm{~d}$ \\
\hline
\end{tabular}

Médias seguidas pela mesma letra, na coluna, não diferem entre si, pelo teste de Tukey, em nível de 5\% de probabilidade.

O material contendo apenas cascas apresentou baixa concentração de $\mathrm{N}$ e de proteína, comparativamente às sementes, notadamente às descascadas. De acordo com o resultado do teste de Tukey, em nível de 5\% de probabilidade, não há diferença significativa entre os teores de proteína bruta nas sementes com massa na faixa média e na faixa de maior massa, e entre estas últimas e as sementes de menor massa, como pode ser visto no Quadro 7.

Ndabigengesere et al. (1995) encontraram teor de 36,7 dag $\mathrm{kg}^{-1}$ de proteína bruta em sementes de moringa descascadas, valores inferiores aos obtidos neste trabalho $\left(44,07 \mathrm{dag} \mathrm{kg}^{-1}\right)$. Em sementes com cascas, esses autores obtiveram 27,1 dag $\mathrm{kg}^{-1}$, valores também inferiores aos obtidos nesse trabalho (na faixa de 27,28 a 35,58 dag $\mathrm{kg}^{-1}$ ).

Com base nos resultados, pode-se verificar que os menores teores de proteína bruta foram obtidos nas cascas e, em seguida, nas sementes de menor massa, talvez por serem as mais mal formadas.
Como esses foram os materiais que produziram extratos de menor eficiência na remoção da turbidez e de coliformes termotolerantes, ficou evidente a associação entre teor de proteína bruta no extrato e a remoção dessas variáveis. Acreditase que sementes com massa maior ou igual a 0,20 $\mathrm{g}$ estariam bem formadas e, consequentemente, com maiores teores de proteína bruta. A tendência de maior teor de proteína nas sementes de massa intermediária (de $0,20 \mathrm{~g} \mathrm{a} 0,30 \mathrm{~g}$ ) que nas de maior massa (maior ou igual a $0,30 \mathrm{~g}$ ) talvez esteja associada ao fator diluição no material vegetal.

Tal como relatado por Ndabigengesere et al. (1995) e verificado por meio de análises estatísticas efetuadas neste trabalho, os maiores teores de proteína bruta são encontrados em sementes descascadas, o que possivelmente implicaria em melhores eficiências no tratamento da água. Por outro lado, diante dos resultados de remoção de sólidos suspensos (turbidez) e de coliformes ( $E$. coli), considera-se que esse aumento no teor de

\section{REVENG}

341-350p. ENGENHARIA NA AGRICULTURA, VIÇOSA - MG, V.22 N.4, JULHO / AGOSTO 2014 
proteínas, proporcionado pelo descascamento das sementes, só é compensador, sob o ponto de vista operacional e econômico, no que se refere ao preparo do coagulante, no caso das sementes apresentarem massa menor que $0,20 \mathrm{~g}$. No caso de sementes de tamanhos diversos, apresentando massa média de 0,20 a $0,30 \mathrm{~g}$, não é recomendável seu descascamento.

\section{CONCLUSÕES}

Com base nos resultados obtidos, pode-se concluir que:

- A adição de extrato de sementes de moringa como agente de coagulação em águas superficiais é eficiente na remoção de turbidez e de coliformes termotolerantes (E. coli), porém, melhores resultados são obtidos quando o extrato é preparado com sementes com massa maior que $0,20 \mathrm{~g}$ ou descascadas;

- A eficiência na remoção $E$. coli e, principalmente, da turbidez esteve diretamente associada ao teor de proteína bruta contido na semente;

- O descascamento de sementes potencializa a ação do agente coagulante da semente da moringa e pode ser importante alternativa para aumento da eficiência de extratos preparados com sementes de massa menor que $0,20 \mathrm{~g}$, na remoção de turbidez e E. coli de águas superficiais.

\section{REFERÊNCIAS BIBLIOGRÁFICAS}

ABDULSALAM, S.; GITAL, A.A.; MISAU, I.M.; SULEIMAN, M.S. Water clarification using Moringa oleifera seed coagulant: maiduguri raw water as a case study. Journal of Food, Agriculture \& Environment, Helsinki, v.5, n.1, p.302-306, 2007.

AMERICAN PUBLIC HEALTH ASSOCIATION - APHA; AMERICAN WATER WORKS ASSOCIATION - AWWA; WATER ENVIRONMENT FEDERATION - WEF. Standard methods for the examination of water and wastewater. 21. ed. Washington: APHA/ AWWA/WEF, 2005. 1268p.

ARANTES, C.C.; SILVA, G.K.; PATERNIANI, J.E.S. Desenvolvimento de sachê para aplicação de coagulante à base de sementes de Moringa oleifera no tratamento de água. II Encontro Nacional de Moringa, 2010. Anais... Aracaju, SE.

BORBA, L.R. Viabilidade do uso da Moringa oleifera Lam no tratamento simplificado de água para pequenas comunidades. 2001. 92f. Dissertação (Mestrado em Desenvolvimento e Meio Ambiente), Universidade Federal da Paraíba, 2001.

CRUZ, M.W.O.; OLIVEIRA, E.G.; ARAÚJO FILHO, J.M.; HIPÓLITO, L.F.; LIMA, C.B. Avaliação de eficiência de sementes de moringa no tratamento de efluentes de viveiros de camarão marinho. Revista Ciências Agronômicas, Fortaleza, v.38, n.3, p.257-263, Jul.-Set., 2007.

DI BERNARDO, L.; DANTAS, A.B. Métodos e Técnicas de Tratamento de Água. 2. ed. São Carlos: RIMA Editora, 2005. v.02. 1565p.

FERREIRA, P.C.; PIAI, K.A.; TAKAYANAGUI, A.M.M.; MUÑOZ, S.I.S. Alumínio como fator de risco para a doença de Alzheimer. Revista LatinoAmericana de Enfermagem, Ribeirão Preto, v.16, n.1, p.151-157, 2008.

JAHN, S.A.A. Proper use of African Natural Coagulants for Rural Water Supplies: Research in the Sudan and a Guide for New Projects. Eschborn, GTZ; Germany, 1986.

LO MONACO, P.A.V.; MATOS, A.T.; RIBEIRO, I.C.A.; NASCIMENTO, F.S.; SARMENTO, A.P. Utilização de extrato de sementes de moringa como agente coagulante no tratamento de água para abastecimento e águas residuárias. AmbiÁgua, Taubaté, v.5, n.3, p.222-231, 2010.

MATOS, A.T. Qualidade do meio físico - Práticas de laboratório. Viçosa: Imprensa Universitária, UFV, 2012. 150p. 
MATOS, A.T.; CABANELLAS, C.F.G.; CECON, P.R.; BRASIL, M.S.; MUDADO, C.S. Efeito da concentração de coagulantes e do $\mathrm{pH}$ da solução na turbidez da água, em recirculação, utilizada no processamento dos frutos do cafeeiro. Engenharia Agrícola, Jaboticabal, v.27, n.2, p.544-551. 2007.

MUYIBI, S.A.; EVISON, L.M. Optimizing physical parameters affeting coagulation of turbid water with Moringa oleifera seeds. Water Research. Londres, v.29, n.12, p.2689-2695, 1995.

NDABIGENGESERE, A.; NARASIAH, K.S.; TALBOLT, B.G. Active agents and mechanism of coagulation of turbid waters using Moringa oleifera. Water Research, Londres, v.29, n.2, p.703-10, 1995.

NDABIGENGESERE, A.; NARASIAH, K.S. Quality of water treated by coagulation using Moringa oleifera seeds. Water Researsh. Londres, v.32, n.3, p.781-791, 1998.

PATERNIANI, J.E.S.; MANTOVANI, M.C.; SANT'ANNA, M.R. Uso de sementes de Moringa oleifera para tratamento de águas superficiais.

Revista Brasileira de Engenharia Agrícola e Ambiental, Campina Grande, v.13, n.6, p.329334. 2009.

PATERNIANI, J.E.S., SILVA, M.J.M., RIBEIRO, T.A.P., BARBOSA, M. Pré-filtração em pedregulho e filtração lenta com areia, manta não tecida e carvão ativado para polimento de efluentes domésticos tratados em leitos cultivados. Engenharia Agrícola, Jaboticabal, v.31, n.4, p.803-812, jul./ago. 2011.
PRITCHARD, M.; CRAVEN, T.; MKANDAWIRE, T.; EDMONDSON, A.S.; O'NEILL, J.G.A comparison between Moringa oleifera and chemical coagulants in the purification of drinking water - An alternative sustainable solution for developing countries. Physics and Chemistry of the Earth, Amsterdam, v.35, p.798-805, 2010.

SANTOS, E.P.C.C.; TEIXEIRA, A.R.; ALMEIDA, C.P.; LIBÂNIO, M.; PÁDUA, V.L. Estudo da coagulação aplicada à filtração direta descendente. Engenharia Sanitária e Ambiental, Rio de Janeiro, v.12, n.04, p.361-370, 2007.

SENGUPTA, M.E.; KERAITA, B.; OLSEN, A.; BOATENG, O.K.; THAMSBORG, S.M.; PÁLSDÓTTIR, G.R.; DAALSGAARD, A. Use of Moringa oleifera seed extracts to reduce helminth egg numbers and turbidity in irrigation water. Water Research, New York, v.46, p.3646-3656, 2012.

SILVA, D.J. Análises de alimentos (métodos químicos e biológicos). Viçosa: UFV. 1998, 2ª . ed. $165 \mathrm{p}$.

SILVA, M.E.R.; AQUINO, M.D.; SANTOS, A.B. Pós-tratamento de efluentes provenientes de reatores anaeróbios tratando esgotos sanitários por coagulantes naturais e não-naturais. Revista Tecnologia, Fortaleza, v.28, n.2, p.178-190, 2007.

WANG, W., YANG, H., WANG, X., JIANG, J. ZHU, W. Effects of fulvic acid and humic acid on aluminum speciation in drinking water. Journal of Environmental Sciences, v.22, p.211-217, 2010. 